\title{
Novas equações para antigas incógnitas: a questão habitacional no Brasil sob a ótica da produção acadêmica nacional $^{1}$
}

\section{New solutions for old uncertainties: academic literature's perspective on the Brazilian housing issue}

\section{Nuevas ecuaciones para antiguas incógnitas: el tema habitacional en Brasil desde la perspectiva de la producción académica nacional}

Paulo Nascimento Neto, doutorando em Gestão Urbana na Pontifícia Universidade Católica do Paraná (PUCPR). E-mail: paulo. nn@uol.com.br.

Tomás Antonio Moreira, Ph.D. em Estudos Urbanos pela Université du Québec à Montréal, Montreal, Canadá, professor do Programa de Pós-Graduação em Urbanismo e do curso de Arquitetura e Urbanismo da Pontifícia Universidade Católica de Campinas (PUCCampinas).E-mail: tomas.moreira@puc-campinas.edu.br.

\section{Resumo}

A questão habitacional no Brasil tem se destacado por grandes avanços nas últimas décadas, tanto no campo acadêmico, quanto em relação à formulação de políticas públicas. Entretanto, apesar do indiscutivel progresso, emergem dúvidas sobre a real efetividade das ações empreendidas e sobre o papel da academia na superação das crônicas deficiências do planejamento urbano no País, que, em última instância, conduzem à escalada do deficit habitacional. A despeito da ampliação do volume de conhecimento produzido, a literatura científica carece de dados que permitam caracterizar esse panorama com consistência. Destarte, procura-se discutir a produção científica

Este trabalho foi desenvolvido com o apoio da Capes por meio de Bolsa de Doutorado concedida pelo Programa de Suporte à Pós-Graduação de Instituições de Ensino Particulares (Prosup). 
nacional sobre habitação com base em um estudo bibliométrico, com maior enfoque para a última década. Os resultados obtidos evidenciam um descolamento dos valores e ideais adotados na práxis da gestão pública e no discurso acadêmico, o que conduz ao questionamento acerca da real contribuição dos pesquisadores na árdua missão de reduzir a segregação social existente em nosso País.

Palavras-chave: Habitação Social. Política Habitacional. Análise Bibliométrica. Produção Científica.

\section{Abstract}

The social housing issue in Brazil has been characterized by great advances in the last decades, both in academic discussions and in public policies. However, despite undeniable progress, some doubts emerge regarding the effectiveness of public guidelines and the role of academia on overcoming chronic problems of Brazilian urban planning that, ultimately, lead to deficits in housing expansion. Despite growth in the volume of scientific knowledge, academia does not have enough data to properly characterize this panorama. Thus, this paper seeks to discuss Brazilian scientific production about housing from a bibliometric point of view, focusing primarily on the last decade. Results point to a detachment of values and ideals adopted in public administration and academic discourse that ultimately raises questions about the real contribution of researchers to the arduous task of reducing social segregation in Brazil.

Keywords: Social Housing. Social Housing Policy.Bibliometric Analysis. Scientific Production.

\section{Resumen}

El tema habitacional en Brasil se ha destacado por los grandes avances en las últimas décadas, tanto en el campo académico, cuanto en la formulación de políticas públicas. Sin embargo, a pesar de lindiscutible progreso, surgen dudas sobre la eficacia real de las acciones emprendidas 
y acerca del papel de la academia en la superación de las deficiencias crónicas de la planificación urbana en el país, que, en última instancia, llevan a la escalada de la escasez de viviendas. A pesar del aumento en el volumen de conocimiento producido, la literatura científica carece de datos que permitan caracterizar este panorama con consistencia. Por lo tanto, se busca en este artículo discutir la producción científica nacional en materia de vivienda a partir de un estudio bibliometrico, con mayor énfasis en la última década. Los resultados obtenidos muestran una separación de valores e ideales adoptados en la práctica de la gestión pública y en el discurso académico que, en última instancia, conduce al cuestionamiento acerca de la contribución real de los investigadores en la difícil tarea de reducir la segregación social existente en nuestro país.

Palabras clave: Vivienda de Interés Social. Política Habitacional. Análisis Bibliometrico. Producción Científica.

\section{Introdução}

As discussões e os estudos sobre a questão habitacional no Brasil têm recebido atenção crescente da academia e dos gestores públicos. De fato, nas últimas décadas, observa-se um progresso significativo dos princípios e das estratégias de atuação das políticas habitacionais brasileiras: de um modelo estandardizado, sem preocupações sociais e urbanísticas na década de 1970, tais políticas passaram por um processo de reformulação conceitual na década de 1990 e se estruturam em bases inovadoras a partir da década de 2000.

Os anos 2000 são particularmente representativos para o campo da habitação de interesse social no Brasil. A definição das diretrizes e dos mecanismos para o cumprimento da função social da cidade, em 2001 (Estatuto da Cidade), a definição das diretrizes e dos instrumentos do marco nacional sobre a política habitacional, em 2004 (Política Nacional de Habitação), a estruturação de sistemas diferenciados para atuação na habitação de mercado e de interesse social, em 2005 (Sistema Nacional de Habitação), e o delineamento das estratégias de equacionamento das necessidades habitacionais até 2023, em 2008 (Plano Nacional de Habitação), estabeleceram um modelo consistente de enfrentamento 
da questão habitacional no País, fortalecendo a articulação das ações e dos recursos das diversas esferas de governo e agentes correlatos (NASCIMENTO NETO; MOREIRA, 2010). Para Rolnik, Nakano e Cymbalista (2008), a abundância de créditos e subsídios - que permitem alcançar os estratos populacionais de menor renda - e o processo sociopolítico estabelecido, finalmente, tornam possível se falar em política de acesso ao solo urbano no Brasil.

Entretanto, apesar dos avanços, estudos recentes evidenciam uma série de limitações à política habitacional brasileira - é recorrente a deficitária integração entre as políticas habitacional e fundiária. A histórica dificuldade dos municípios em controlar o uso e ocupação do solo e produzir cidades ex ante constitui um dos principais desafios dos gestores públicos, e nessa linha a Política Nacional de Habitação arrisca incorrer em erros semelhantes aos ocorridos no modelo BNH (Banco Nacional de Habitação), produzindo e reproduzindo um modelo caracterizado pela segregação socioterritorial e pela precariedade urbana e ambiental (BONDUKI, 2008; ROLNIK; NAKANO; CYMBALISTA, 2008; ROLNIK; KLINK, 2011).

Para Maricato (2011), esses desafios somente serão superados com a intersecção de conhecimentos empíricos e científicos, tornando possivel formular diretrizes urbanas compativeis com a realidade local e superando muitas das deficiências crônicas do planejamento urbano no Brasil. Nesse contexto, o constante aprofundamento do conhecimento científico se faz essencial, tendo como resultado mensurável o aumento quantitativo e qualitativo das publicações científicas.

Como produtos da ciência, as publicações se constituem, sem dúvidas, em instâncias privilegiadas para o estudo do comportamento de dada disciplina ou campo científico, sob os mais variados aspectos, respondendo a diferentes questões: quais são as frentes de pesquisas desse campo, considerando-se diferentes variáveis, pesquisadores/ autores, instituições ou temas; quais são os padrões de comunicação entre seus pares, tais como os tipos de canais preferidos e as parcerias; quais são as bases epistemológicas em que se fundamentam suas pesquisas: autores, títulos clássicos, línguas, países, datas, dentre outras (ARAÚJO; ALVARENGA, 2011, p. 56). 
Embora haja uma relativa constância do interesse acadêmico sobre a temática, observa-se na última década um aumento expressivo no número de artigos científicos, dissertações e teses produzidas sobre as estratégias de atuação empreendidas pelo poder público a partir da aprovação do Estatuto da Cidade e da formulação da Política Nacional de Habitação.

A despeito da perceptível ampliação do volume de conhecimento produzido, a literatura científica carece de dados que permitam investigar essa hipótese com maior consistência. Destarte, é de extrema relevância o desenvolvimento de estudos que mapeiem e avaliem a imensa quantidade de conhecimento científico produzido nos últimos anos sobre a questão habitacional no Brasil. Essa empreitada, embora constitua uma tarefa árdua e morosa, é fundamental para promover um maior entendimento sobre a comunidade científica ligada à temática, identificando o seu foco predominante, bem como a forma pela qual esse escopo se transforma ao longo do tempo.

O entendimento desses padrões temporais se fundamenta no esquema analítico de Kuhn (2011), para quem as revoluções científicas ocorrem de modo descontínuo, em saltos qualitativos a partir dos quais há quebras de paradigmas. Nos intervalos dessas revoluções científicas, a ciência obedeceria a um relativo dogmatismo, pautando-se segundo modelos hegemônicos compostos por conjuntos semelhantes de valores, teorias e métodos (FRANCELIN, 2004).

Assim, compreender a evolução da discussão acadêmica sobre a questão habitacional no Brasil permite não somente obter uma visão panorâmica sobre o tema, mas também identificar eventuais pontos de ruptura, nos quais, nas palavras de Mocelin (2009, p. 43), “nasce um novo paradigma, que traz consigo uma nova visão da práxis científica, incorporando novos temas prioritários, novas técnicas, métodos, hipóteses e teorias".

Nesse contexto, impõe-se a seguinte questão-problema: a produção científica nacional efetivamente acompanha a cronologia da política habitacional no Brasil, ou há um descompasso entre o 
entendimento dos formuladores de políticas públicas e os pesquisadores acadêmicos?

A fim de permitir a mensuração e posterior análise da produção cientifica, adotou-se a bibliometria como método de pesquisa, investigando os trabalhos disponiveis no Banco de Teses e Dissertações da Capes, os artigos publicados nos periódicos Cadernos Metrópole e Revista Brasileira de Estudos Urbanos e Regionais (Rbeur)e os trabalhos aceitos para comunicação oral no Encontro Nacional da Associação Nacional de Pós-Graduação e Pesquisa em Planejamento Urbano e Regional (Enanpur), dentro do recorte temporal da última década.

Com vistas a atingir os objetivos delineados, este artigo está organizado em três grandes seções: inicialmente, discute questões de ordem metodológica, os critérios adotados e suas limitações; na sequência, procede à análise bibliométrica dos dados obtidos nas fontes de pesquisa supracitadas, e, por fim, discute os resultados alcançados, procurando relacioná-los à premente necessidade de integração do conhecimento científico ao conhecimento empírico.

\section{Metodologia de pesquisa}

Buscando atingir os objetivos propostos nesta pesquisa, adotouse a bibliometria como método de pesquisa e, com base nela, se discute a produção científica nacional sobre habitação, com maior enfoque para a última década. Os estudos bibliométricos se estruturam por meio de um conjunto de técnicas estatísticas e matemáticas utilizadas para mapear o conhecimento de determinado campo científico e analisar o comportamento dos pesquisadores em suas decisões na construção desse conhecimento (CALDAS; TINOCO, 2004; ARAÚJO, 2006).

A realização desse tipo de estudo representa um esforço de significativa relevância no aprofundamento do conhecimento sobre a produção científica de um país, permitindo caracterizar quantitativamente o comportamento e a evolução de determinada área do conhecimento (ARAÚJO; ALVARENGA, 2011). 
Adota-se, neste artigo, a teoria epidêmica da transmissão de ideias, desenvolvida, em 1967, por Goffman e Newill (apud ARAÚJ0, 2006), segundo a qual a propagação de uma hipótese ou teoria dentro de uma comunidade se equipara ao fenômeno de transmissão de uma doença contagiosa. Para Weitzel (2006), o processo de construção, propagação e uso da informação científica constitui elemento básico da própria estrutura da comunidade científica, na qual é possível identificar uma linha do tempo que acompanha o progresso do conhecimento, desde sua produção, passando pela interação com novos trabalhos e culminando na compilação em outros trabalhos de revisão de literatura.

De forma complementar ao estudo bibliométrico, adotou-se a metodologia de Análise de Redes Sociais (Social Network Analysis - SNA) com o objetivo de investigar, dentro do universo de artigos e comunicações orais pesquisados, a rede de relacionamento estabelecida entre os pesquisadores.

A SNA é uma metodologia de origem multidisciplinar, que apresenta como principal vantagem a formalização gráfica e quantitativa de processos e propriedades específicas de uma realidade social. Sua aplicação como método descritivo data dos anos 1950 e se baseia na leitura das redes como um conjunto de nós (nodes) unidos por elos (ties), formando sociogramas (representação visual) e matrizes (representação numérica), o que permite a visualização de relações e padrões (SOUZA; QUANDT, 2008). Para Duarte e Frey (2008), pode-se enxergar a rede como um conjunto de relações instáveis que se desenvolvem por intermédio de regras de funcionamento, dependente da velocidade e da flexibilidade, que, juntas, dão à rede um caráter extremamente mutável, no qual ligações se fazem e se desfazem no tempo.

Para este trabalho, foi utilizada a teoria dos grafos como metodologia de análise da rede de autores dentro do universo pesquisado de trabalhos científicos. No processamento dos dados, foram utilizados os softwares UClnete NetDraw. 


\section{Amostra de Pesquisa}

No volumoso universo de publicações científicas disponíveis no Brasil, procurou-se definir, para esta pesquisa, um recorte amostral amplo que abrangesse produções relacionadas aos programas de pós-graduação stricto sensu, aos periódicos científicos de consistência editorial da área de Planejamento Urbano e Regional/Demografia (PUR/D) e aos eventos científicos de abrangência nacional também na área de PUR/D.

A amostra de Planejamento Urbano e Regional/Demografia constitui uma das áreas de concentração categorizadas pela Capes, na qual se situa um grande volume de publicações relacionadas à questão habitacional. Concomitantemente, deve-se ressaltar a área de concentração de Arquitetura e Urbanismo, que, embora também se destaque em relação à temática, não foi contemplada neste estudo.

Em cada uma das amostras específicas mencionadas, procedeuse à busca por cinco palavras-chave que permitissem localizar adequadamente o maior número de publicações sobre a temática habitacional no Brasil. Sua seleção ocorreu a partir da experiência acadêmica e profissional dos autores na área. Desse modo, foram utilizadas as seguintes palavras-chave: Habitação de Interesse Social, Direito à Moradia, Estatuto da Cidade², Ocupação Irregular e Regularização Fundiária.

É necessário salientar que a pesquisa realizada apresenta restrições de ordem metodológica, visto que a utilização de determinadas palavras-chave ou a designação de determinados fenômenos são inevitavelmente datadas, podendo influenciar os resultados obtidos. Todavia, entende-se que limitações de pesquisa são características intrínsecas à sua própria natureza e estão diretamente relacionadas

20 termo Estatuto da Cidade, ainda que não exprima uma relação direta com a temática habitacional, foi incluído tendo em vista sua intrínseca relação com o direito à cidade e à propriedade, questão central da discussão habitacional nas últimas décadas. ao desenvolvimento de trabalhos futuros.

Os levantamentos de dados foram conduzidos utilizando-se sempre a expressão exata, buscada no conjunto composto pelo resumo, pelo título e pelas palavras-chave da publicação. Para o caso específico dos itens pesquisados que não dispunham de resumo, o primeiro capítulo da publicação (referente à introdução) foi incorporado à busca. 
Em relação à produção dos programas de pós-graduação stricto sensu, utilizou-se como fonte de pesquisa o Banco de Teses e Dissertações da Capes, significativo e oficialmente reconhecido referencial da produção científica brasileira. Para Ultramari, Firmino e Silva (2011, p. 9)، "seu acesso livre, série histórica e permissão para várias perspectivas de análise o qualificam como singular fonte de pesquisa", sendo "útil para uma análise quantitativa da atividade de investigação da ciência e tecnologia” (ARAÚJO; ALVARENGA, 2011, p. 52).

O acervo de teses e dissertações disponíveis no banco da Capes abrange o período de 1987 a 2009, e nele foi desenvolvido um primeiro levantamento. A segunda etapa desta pesquisa, mais aprofundada, foi, então, engendrada apenas para o período de 1996 a 2009, haja vista que somente a partir desse ano as teses e dissertações passaram a ser classificadas por grandes áreas do conhecimento ${ }^{3}$.

Quanto aos periódicos científicos, buscaram-se dois de consistência editorial da área de PUR/D, com mais de dez anos de existência, que foram adotados como amostra de pesquisa: Cadernos Metrópole, editado desde 1999, pelo Observatório das Metrópoles, com 24 edições e 205 artigos; e Revista Brasileira de Estudos Urbanos e Regionais (Rbeur), editada desde 1999, pela Associação Nacional de Pósgraduação e Pesquisa em Planejamento Urbano e Regional (Anpur), com 24 edições e 142 artigos. Para a presente pesquisa, o recorte temporal analisado limitou-se ao período de 2000 a 2010, englobando 324 artigos.

Por fim, em relação aos eventos científicos, optou-se por analisar os artigos aceitos para comunicação oral em sessões temáticas no Encontro Nacional da Anpur (Enanpur), principal evento da área de PUR/D, de abrangência nacional e periodicidade bienal. Para a presente pesquisa, o recorte temporal analisado também se limitou ao período de 2000 a 2010 (envolvendo, então, os encontros ocorridos entre 2001 e 2009), reunindo um total de 1.302 artigos.

Em face das amostras definidas (dissertações e teses disponíveis no Banco da Capes, Cadernos Metrópole, Rbeur e Enanpur), procedeu-se à pesquisa por palavra-chave conforme já mencionado anteriormente. Para as dissertações e teses, os resultados encontrados foram categorizados

3 Ciências Agrárias, Ciências Biológicas, Ciências da Saúde, Ciências Exatas e da Terra, Ciências Humanas, Ciências Sociais Aplicadas, Engenharias, Multidisciplinar e Linguística, Letras e Artes. 
por ano de defesa e por grande área à qual estão vinculados. Para os resultados encontrados nas demais amostras adotadas, foi analisado o volume publicado por ano, sua relevância dentro do periódico/ evento pesquisado e a rede de relacionamento estabelecida entre os pesquisadores. A seguir, são apresentados os resultados obtidos, com base nos quais se desenvolveu a análise que a procede.

\section{A produção científica sobre habitação social no Brasil}

\section{a. Banco de Teses e Dissertações da Capes}

Conforme anteriormente exposto, a busca por teses e dissertações no banco da Capes relacionadas à temática habitacional brasileira foi empreendida mediante a procura pelas cinco palavraschave supramencionadas, sempre pesquisadas segundo sua expressão exata.

O levantamento desenvolvido resultou em um conjunto de 826 dissertações e 105 teses, defendidas entre 1987 e 2009. Percebe-se um significativo aumento da produção acadêmica sobre a temática habitacional a partir do final da década de 1990, o que se expressa no incremento da adoção de todas as palavras-chave nos trabalhos de mestrado e doutorado (Gráfico 1 e Gráfico 2).

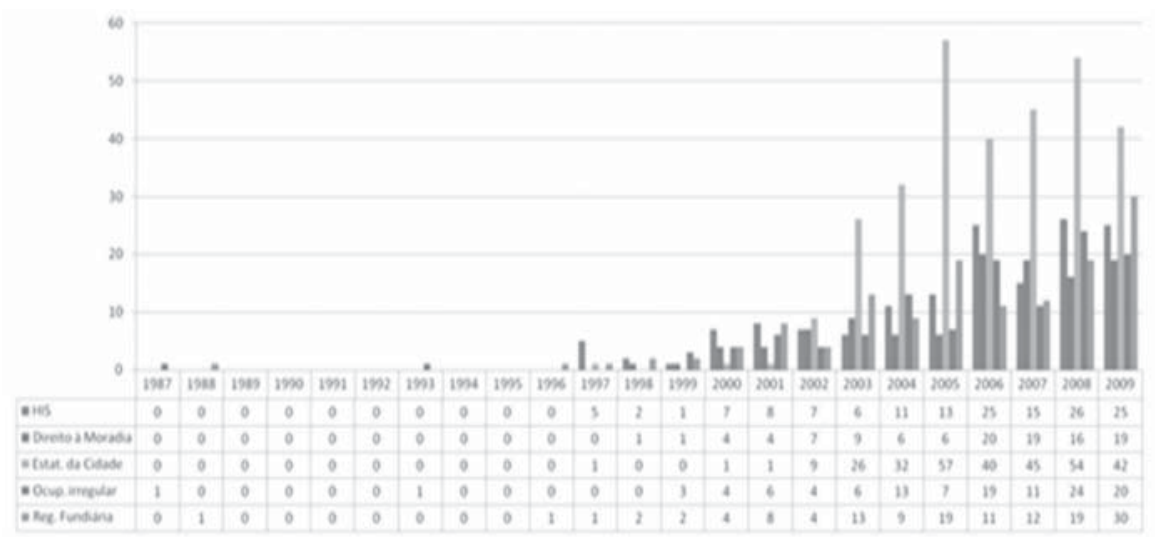

Fonte: Capes (2011). Elaboração dos autores

Gráfico 1. Uso das palavras-chave pesquisadas em dissertações de mestrado, 1987 a 2009 


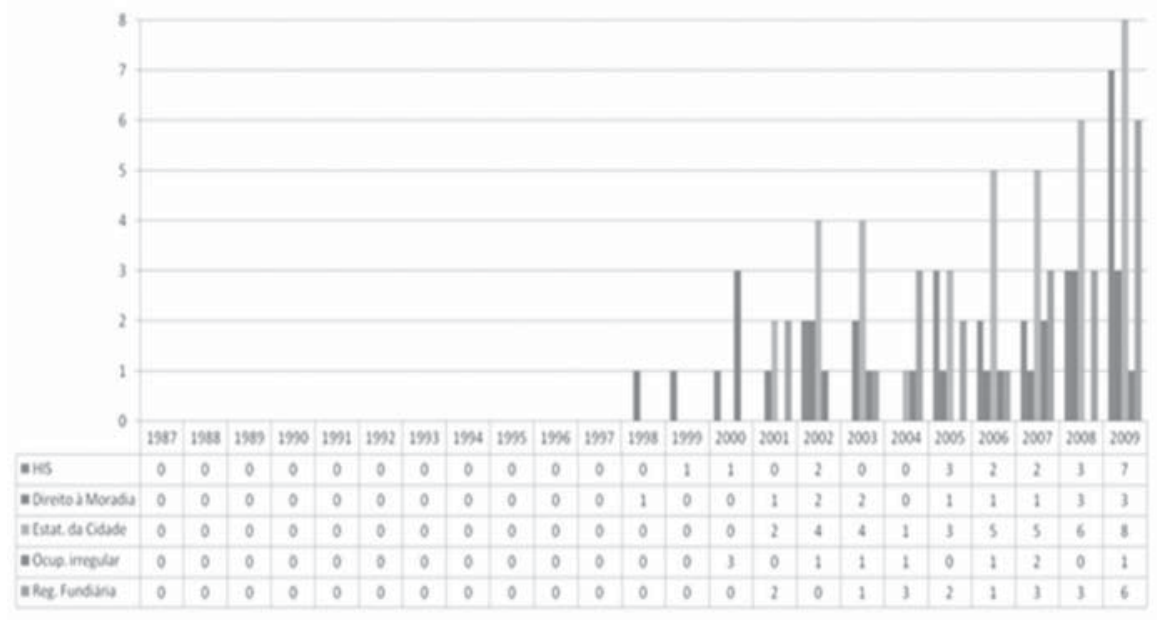

Fonte: Capes (2011). Elaboração dos autores.

\section{Gráfico 2. Uso das palavras-chave pesquisadas em teses de doutorado, 1987 a 2009}

É interessante observar que expressões que pressupunham uma utilização expressiva desde as décadas de 1970 e 1980, como é o caso de Direito à Moradia e Ocupação Irregular', somente passaram a constituir objeto de pesquisa de alunos de mestrado e doutorado no final da década de 1990. Essa constatação permite especular sobre a relativa demora da academia em absorver temáticas relevantes para a sociedade e que já integram o debate nacional sobre a questão urbana há muito tempo.

Como exemplo, pode-se tomar os resultados obtidos para a expressão Estatuto da Cidade, cuja recorrência tornou-se expressiva a partir de 2003. Apesar da absorção quase que instantânea nas dissertações e teses após a aprovação da Lei n 10.257, de 2001 (considerando o gap de dois anos decorrente do tempo médio de elaboração de uma dissertação), deve-se recordar que discussões envolvendo esse marco legal remontam à década de 1980. Assim, evidencia-se certa negligência da academia em relação ao tema até a formatação de um volume significativo de material de apoio para discussão (entendido aqui como a aprovação da referida legislação). Complementarmente, as expressões Habitação de Interesse Social (HIS) e Regularização Fundiária também adquirem maior interesse após a
${ }^{4}$ A luta pelo direito à moradia adquire expressividade a partir da década de 1970, decorrente dos efeitos perversos da urbanização acelerada (FERREIRA, 2003). Nesse contexto, Rolnik (2009) ressalta a importância do Movimento Nacional pela Reforma Urbana, defendendo o direito à cidade e à moradia digna. 
aprovação do Estatuto da Cidade, quando, então, se estabeleceram as bases legais que balizam a temática até os diais atuais.

Estudos recentes na área de Administração (CALDAS; TINOCO, 2004; TONELLI et al., 2003), na área contábil (SÖTHE; KROENKE; BEZERRA, 2011) e na área de Planejamento Urbano (ULTRAMARI; FIRMINO; SILVA, 2011) especulam sobre essa certa acomodação da comunidade acadêmica, que tende a permanecer em uma zona de conforto onde há vasta disponibilidade de material relativo a pesquisas anteriores, as bases teóricas já são amplamente aceitas e os resultados obtidos dificilmente são questionáveis.

Compreender esse panorama segundo a teoria epidêmica da transmissão de ideias de Goffman e Newill (apud ARAÚJO, 2006) e a estrutura das revoluções científicas de Thomas Kuhn (2011) significa enxergar a produção de dissertações e teses sob um ponto de vista polêmico: permite-se questionar a relevância de tamanho volume de produção científica para a melhoria da sociedade - o que, acredita-se, deveria ser o objetivo principal da ciência. Castiel e Sanz-Valero (2007, p. 3042) afirmam que,

Com a enorme ampliação do número de revistas e artigos, não à toa começa-se a conviver com a sensação de haver algo de desarrazoado diante desta cornucópia de artigos científicos. Ela se dá, a um só tempo, não só em quantidades enormes e de forma acelerada, mas também apresentando, embutida em sua proliferação, uma perspectiva duvidosa quanto à avaliação da respectiva fertilidade nos processos de construção do conhecimento [...] Existem (e existirão) muitos artigos que jamais serão lidos. Este dado é difícil de ser estimado. Há, todavia, estimativas de que cerca de $50 \%$ dos trabalhos em ciências sociais publicados jamais serão citados.

Complementarmente à análise realizada, é interessante verificar de que forma esses trabalhos se dividem dentro das grandes áreas de conhecimento estabelecidas pela Capes. Conforme mencionado anteriormente, para viabilizar esta análise, o recorte temporal foi reduzido para o período de 1996 a 2009, haja vista que, em relação aos anos anteriores, a área do conhecimento indicada nas teses e dissertações não segue um padrão passível de compatibilização. 
Diante dos dados levantados, apresentados no Gráfico 3, observa-se claro predomínio das Ciências Sociais Aplicadas na discussão de questões relacionadas à temática habitacional em todas as palavraschave, representando, inclusive, mais de $80 \%$ dos trabalhos para a expressão "Direito à Moradia”.

\begin{tabular}{|l|l|l|l|l|l|}
\hline & & & & & \\
\hline
\end{tabular}

Fonte: Capes (2011). Elaboração dos autores.

\section{Gráfico 3. Trabalhos por palavra-chave, pesquisa e grande área do conhecimento (1996 a 2009)}

Essa preponderância se justifica pelo próprio escopo da área do conhecimento, haja vista o fato de que, nas Ciências Sociais Aplicadas, se encontram as subáreas de Planejamento Urbano e Regional, Arquitetura e Urbanismo e Direito (neste caso, Direito Urbanístico), cujo cerne das discussões se concentra na cidade e no urbano, temáticas profundamente relacionadas à questão habitacional.

Deve-se salientar também a tendência de variação do interesse de determinada área do conhecimento, a depender da abrangência da palavra-chave analisada. Assim, apesar de temas como Direito à Moradia e Estatuto da Cidade estarem concentrados nas Ciências Sociais Aplicadas e Ciências Humanas ${ }^{5}$, outros termos suscitam discussões em

${ }^{5}$ Com predomínio das subáreas de Planejamento Urbano e Regional, Arquitetura e Urbanismo e Direito para a primeira e Geografia e Sociologia para a segunda. 
diversas áreas. Nesse sentido, as expressões Habitação de Interesse Social e Ocupação Irregular apresentaram um significativo percentual de trabalhos relacionados às Engenharias (onde se destacam trabalhos de avaliação pós-ocupação e de patologia das edificações).

Complementarmente ao exposto, o Gráfico 4 mostra a evolução temporal do uso das palavras-chave pesquisadas segundo as grandes áreas do conhecimento. Como pode ser observado, os termos Estatuto da Cidade, Direito à Moradia e Regularização Fundiária, embora sejam objeto de trabalhos em diversas áreas, historicamente apresentam concentração nas Ciências Sociais Aplicadas. Já a expressão Ocupação Irregular expõe uma grande variação de interesse entre as diversas áreas do conhecimento ao longo do tempo, em que se não se identifica o predomínio de uma área. O termo Habitação de Interesse Social, conforme já comentado, possui um equilíbrio de interesse entre as Ciências Sociais Aplicadas e as Engenharias, em razão da sobreposição de significados, podendo se relacionar à habitação de interesse social como política pública de superação do deficit habitacional ou edificação relacionada ao uso de habitação popular.

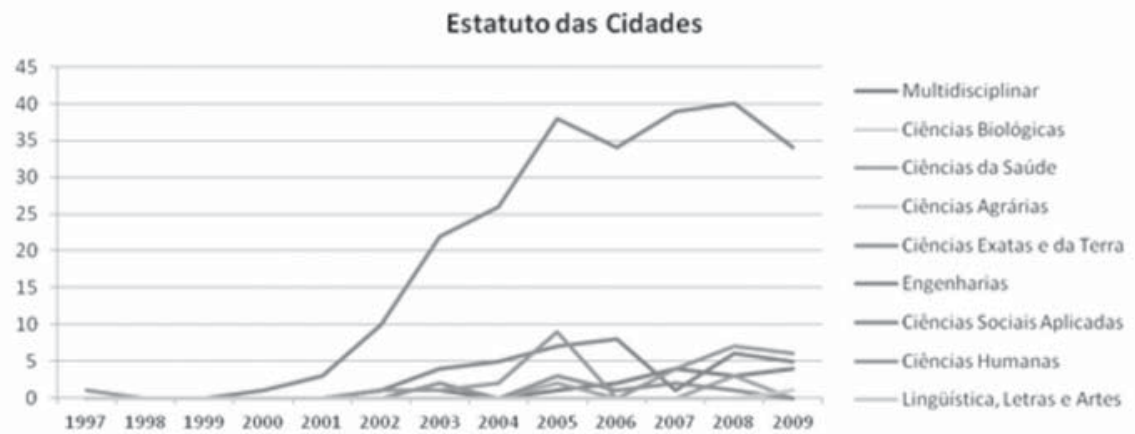

Habitação de Interesse Social

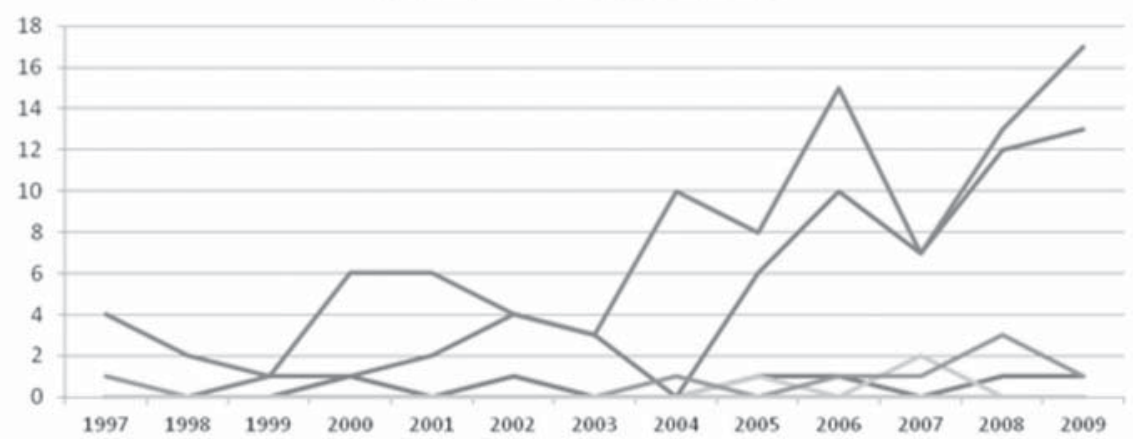




\section{Direito a Moradia}

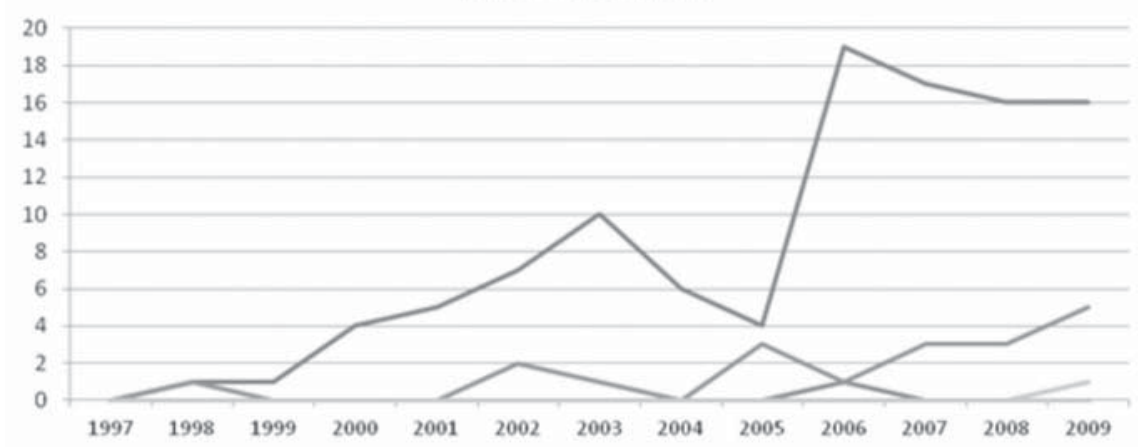

\section{Ocupação Irregular}
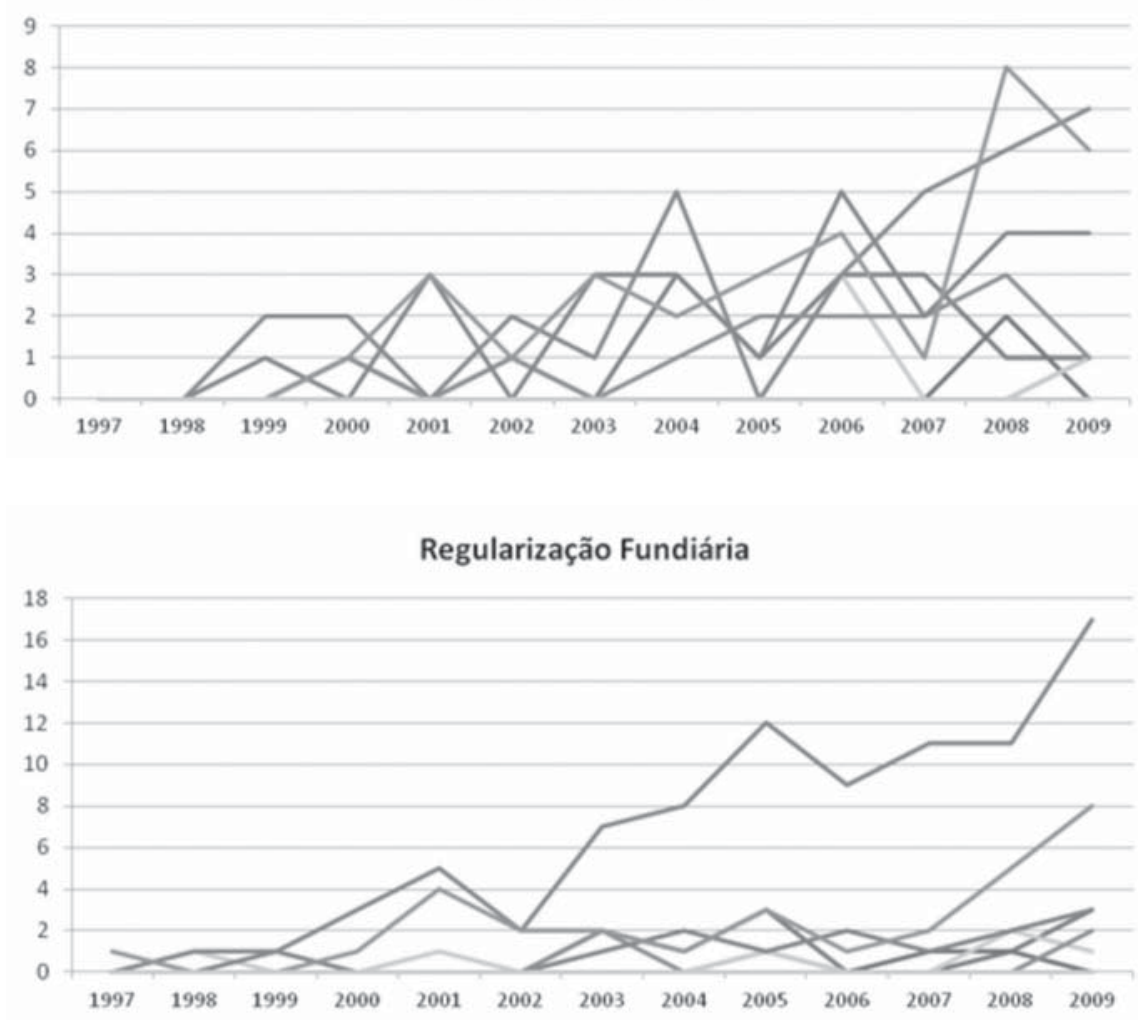

Fonte: Capes (2011). Elaboração dos autores.

Gráfico 4. Total de trabalhos por palavra-chave pesquisada e grande área do conhecimento (1996 a 2009) - evolução temporal 
Por fim, é necessário situar o volume de trabalhos envolvendo a questão habitacional no universo de dissertações e teses publicadas. Conforme se pode perceber na Tabela 1, apesar da baixa representatividade da temática em relação ao número total de mestres e doutores titulados, destaca-se a crescente participação do tema, que passou de 0,047\% do total de dissertações e 0,021\% do total de teses, em 1999, para 0,350\% e $0,218 \%$, em 2009 , o que equivale a um crescimento de $86,57 \%$ e $90,36 \%$, respectivamente, em apenas uma década.

Tabela 1. Relação entre o número de trabalhos encontrados por palavraschave e o número de alunos titulados como mestres e doutores, 1987 a 2009

\begin{tabular}{|ccccccc|}
\hline Ano & $\begin{array}{c}\text { Mestres } \\
\text { titulados }\end{array}$ & $\begin{array}{c}\text { Disserta- } \\
\text { cões encon- } \\
\text { tradas }\end{array}$ & $\begin{array}{c}\text { Repre- } \\
\text { sentati- } \\
\text { vidade }\end{array}$ & $\begin{array}{c}\text { Doutores } \\
\text { titulados }\end{array}$ & $\begin{array}{c}\text { Teses } \\
\text { encontra- } \\
\text { das }\end{array}$ & $\begin{array}{c}\text { Repre- } \\
\text { sentati- } \\
\text { vidade }\end{array}$ \\
\hline 1987 & 3.647 & 1 & $0,027 \%$ & 868 & 0 & $0,000 \%$ \\
\hline 1988 & 3.916 & 1 & $0,026 \%$ & 921 & 0 & $0,000 \%$ \\
\hline 1989 & 4.727 & 0 & $0,000 \%$ & 1.047 & 0 & $0,000 \%$ \\
\hline 1990 & 5.737 & 0 & $0,000 \%$ & 1.302 & 0 & $0,000 \%$ \\
\hline 1991 & 6.811 & 0 & $0,000 \%$ & 1.489 & 0 & $0,000 \%$ \\
\hline 1992 & 7.394 & 0 & $0,000 \%$ & 1.766 & 0 & $0,000 \%$ \\
\hline 1993 & 7.609 & 1 & $0,013 \%$ & 1.803 & 0 & $0,000 \%$ \\
\hline 1994 & 7.821 & 0 & $0,000 \%$ & 2.113 & 0 & $0,000 \%$ \\
\hline 1995 & 9.265 & 0 & $0,000 \%$ & 2.528 & 0 & $0,000 \%$ \\
\hline 1996 & 10.499 & 1 & $0,010 \%$ & 2.985 & 0 & $0,000 \%$ \\
\hline 1997 & 11.922 & 7 & $0,059 \%$ & 3.620 & 0 & $0,000 \%$ \\
\hline 1998 & 12.351 & 5 & $0,040 \%$ & 3.915 & 1 & $0,026 \%$ \\
\hline 1999 & 14.981 & 7 & $0,047 \%$ & 4.831 & 1 & $0,021 \%$ \\
\hline 2000 & 17.821 & 20 & $0,112 \%$ & 5.318 & 4 & $0,075 \%$ \\
\hline 2001 & 20.013 & 27 & $0,135 \%$ & 6.040 & 5 & $0,083 \%$ \\
\hline 2002 & 24.444 & 31 & $0,127 \%$ & 6.894 & 9 & $0,131 \%$ \\
\hline 2003 & 27.649 & 60 & $0,217 \%$ & 8.094 & 8 & $0,099 \%$ \\
\hline 2004 & 26.658 & 71 & $0,266 \%$ & 8.093 & 5 & $0,062 \%$ \\
\hline 2005 & 30.634 & 102 & $0,333 \%$ & 8.989 & 9 & $0,100 \%$ \\
\hline 2006 & 32.261 & 115 & $0,356 \%$ & 9.366 & 10 & $0,107 \%$ \\
\hline 2007 & 32.890 & 102 & $0,310 \%$ & 9.915 & 13 & $0,131 \%$ \\
\hline & & & & & & 0 \\
\hline
\end{tabular}




\begin{tabular}{|ccccccc|} 
Ano & $\begin{array}{c}\text { Mestres } \\
\text { titulados }\end{array}$ & $\begin{array}{c}\text { Disserta- } \\
\text { cões encon- } \\
\text { tradas }\end{array}$ & $\begin{array}{c}\text { Repre- } \\
\text { sentati- } \\
\text { vidade }\end{array}$ & $\begin{array}{c}\text { Doutores } \\
\text { titulados }\end{array}$ & $\begin{array}{c}\text { Teses } \\
\text { encontra- } \\
\text { das }\end{array}$ & $\begin{array}{c}\text { Repre- } \\
\text { sentati- } \\
\text { vidade }\end{array}$ \\
\hline 2008 & 36.014 & 139 & $0,386 \%$ & 10.711 & 15 & $0,140 \%$ \\
\hline 2009 & 38.827 & 136 & $0,350 \%$ & 11.488 & 25 & $0,218 \%$ \\
\hline Total & $\mathbf{3 9 3 . 8 9 1}$ & $\mathbf{8 2 6}$ & $\mathbf{0 , 2 1 0 \%}$ & $\mathbf{1 1 4 . 0 9 6}$ & $\mathbf{1 0 5}$ & $\mathbf{0 , 0 9 2 \%}$ \\
\hline
\end{tabular}

Fonte: Capes (2011). Elaboração dos autores.

\section{b. Periódicos científicos}

De forma a obter um panorama completo da produção científica brasileira sobre a temática habitacional, faz-se necessário mensurar, de maneira complementar às teses e dissertações, o conhecimento produzido com a publicação de artigos em periódicos científicos, uma forma de comunicação científica mais ágil e que, supostamente, deveria se relacionar de maneira mais próxima às ideias e aos ideais vigentes na práxis da gestão pública e do planejamento urbano.

Alinhado à metodologia previamente exposta, o estudo bibliométrico foi empreendido nos periódicos científicos Cadernos Metrópole e Revista Brasileira de Estudos Urbanos e Regionais, pesquisando a recorrência das palavras-chave ${ }^{6}$ escolhidas dentro do universo de 324 artigos publicados entre 2000 e 2010. A busca foi conduzida utilizando-se a expressão exata, procurada dentro do conjunto composto pelo resumo, título e palavras-chave da publicação. Para o caso específico dos artigos que não dispunham de resumo, o primeiro capítulo da publicação foi incorporado à busca.

Conforme o exposto no Gráfico 5, percebe-se um aumento do volume de publicações sobre habitação nos periódicos selecionados, revelando um padrão equivalente ao observado nas teses e dissertações.

6 Habitação de Interesse social, Direito à Moradia, Estatuto da Cidade, Ocupação Irregular e Regularização Fundiária. 


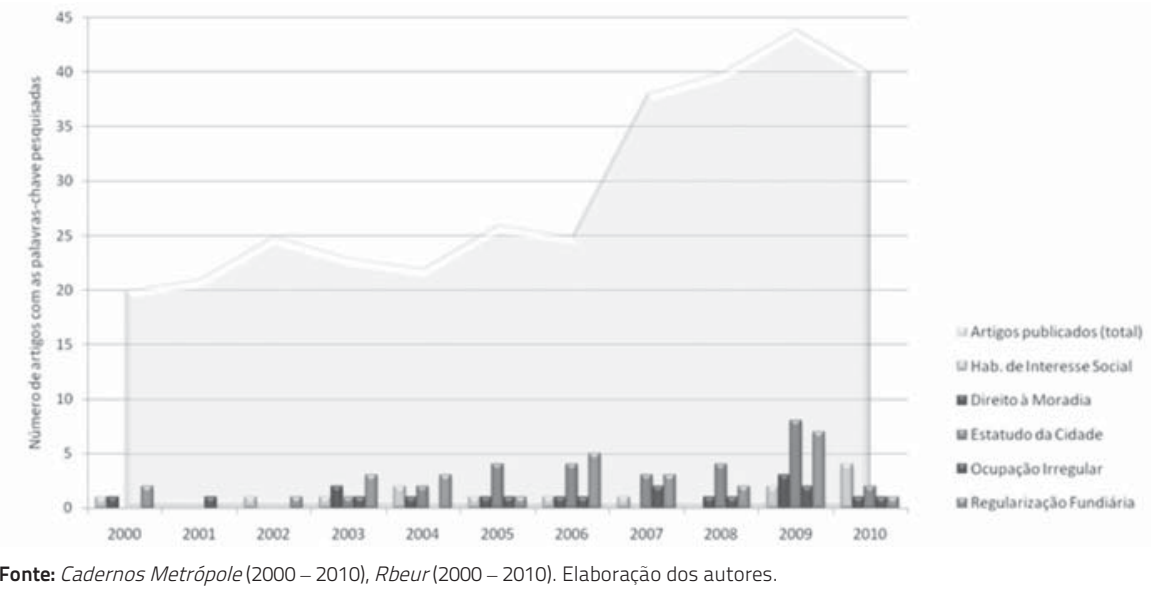

\section{Gráfico 5. Uso das palavras-chave pesquisadas nos periódicos selecionados, 2000 a 2010}

Embora o incremento ocorra em todas as palavras-chave pesquisadas, as temáticas relacionadas com Estatuto da Cidade e Regularização Fundiária concentraram um maior número de publicações a partir de 2003, reiterando as constatações realizadas no item anterior. Nesse contexto, percebe-se uma estreita relação entre as temáticas de interesse de dissertações e teses e o volume de artigos publicados sobre determinado assunto, evidenciando um possível papel dos periódicos como meios de comunicação dos resultados alcançados em pesquisas de mestrado e doutorado.

Se a hipótese construída efetivamente refletir a realidade, delineia-se um panorama não muito otimista para a construção do conhecimento científico em nosso País. Destarte, a imagem existente dos periódicos científicos como formas mais ágeis de comunicação científica - e que, portanto, estariam mais próximas da realidade vivenciada - torna-se frágil e combatível. Deve-se ainda ressaltar que grande parte dos artigos submetidos a periódicos científicos, em geral, envolve resultados preliminares ou parciais de dissertações e teses, gerando um fluxo de contínua reprodução de determinada parcela de um estudo sem, necessariamente, contribuir com o conhecimento científico. Para Castiel e Sanz-Valero, 
[...] neste contexto de ampliação na pesquisa científica e da intensa contabilização numérica de artigos publicados por investigadores em revistas científicas de reconhecido status acadêmico [...] uma pesquisa é fatiada em unidades menores publicáveis para se tornarem vários artigos distribuídos em diferentes revistas. [...] Em outras palavras: um mesmo conteúdo pode aparecer em vários artigos, após receber pequenas mudanças cosméticas. A autocitação pode constituir-se no chamado “autoplágio”. Já há revistas que solicitam na declaração que se costuma fazer na entrega dos originais um item especificando não se tratar de publicação redundante. Outro aspecto importante seria se o artigo traz algo ao conhecimento ou à discussão científica, isto é, se é pertinente, relevante e "revelante" (2007, p. 3042).

Nesse ponto, é importante salientar que, com as análises em curso, não se procura de forma alguma desqualificar os periódicos objetos desta pesquisa, meios de comunicação científica de reconhecida consistência editorial, qualidade e atualidade no conteúdo publicado. Distante disso, a pretensão deste trabalho é expor e debater uma tendência observada em âmbito nacional (e possivelmente internacional) também discutida em outras áreas do conhecimento?.

Paralelamente ao exposto, o Gráfico 5 ainda revela uma possível redução do interesse sobre a temática habitacional, esboçada no ano de 2010, com a vertiginosa diminuição de artigos relacionados às palavras-chave pesquisadas. O termo Habitação de Interesse Social constitui exceção a essa tendência, podendo denotar uma alteração de foco no interesse nas pesquisas.

Independentemente das variações identificadas, verifica-se que a questão habitacional abarca um limitado número de artigos quando comparado ao volume total de artigos publicados anualmente nos dois periódicos analisados (Gráfico 6).
7 Tonelli et al. (2003); Caldas; Tinoco (2004) em relação à área de administração e Castiel; Sanz-Valero (2007) em relação à área de saúde pública. 


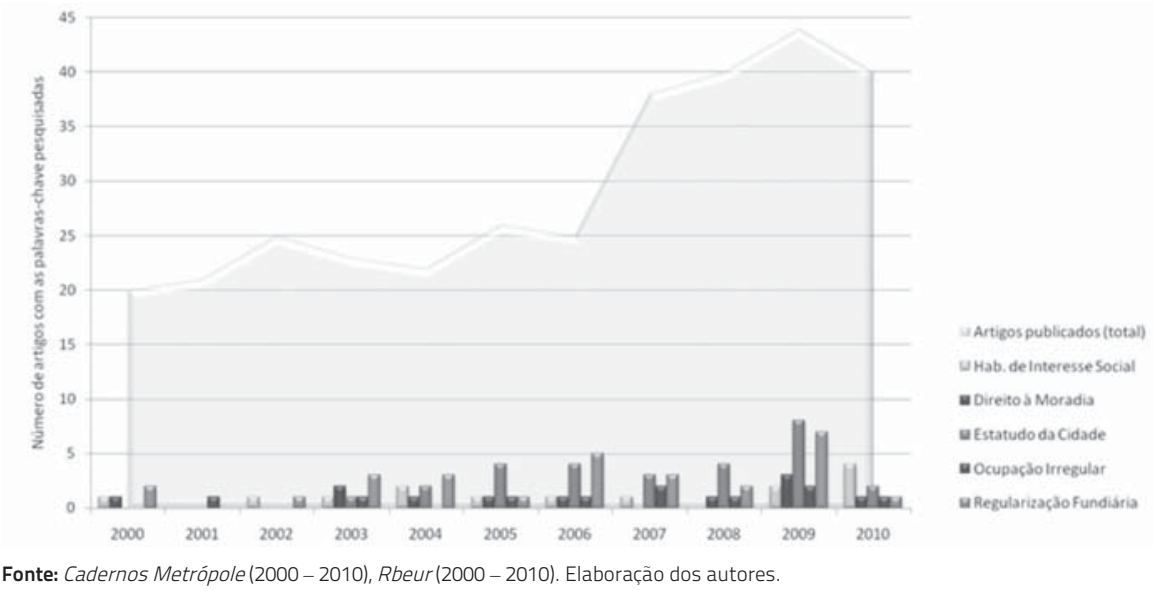

\section{Gráfico 6. Uso das palavras-chave pesquisadas e total de artigos publicados nos periódicos selecionados (2000 a 2010)}

\section{c. Eventos científicos}

Conjuntamente, os periódicos e os eventos científicos constituem um relevante canal de transmissão e discussão de novos conhecimentos, caracterizando-se pela reunião de pesquisadores, profissionais e estudantes de determinada área do conhecimento com o objetivo de apresentar e discutir suas pesquisas com seus pares. Alinhando-se aos procedimentos metodológicos já expostos, para o estudo bibliométrico de sua produção, optou-se por analisar os artigos aceitos para comunicação oral em sessões temáticas dos encontros nacionais da Anpur entre 2001 a 2009, abrangendo um universo de 1.302 artigos.

Conforme pode ser observado no Gráfico 7, dá-se uma manutenção da tendência já identificada nos estudos empreendidos junto ao Banco de Teses e Dissertações da Capes e aos periódicos científicos. Há um crescimento do interesse temático dos trabalhos apresentados entre 2001 e 2009, com destaque para o uso da expressão Estatuto da Cidade a partir de 2003, portanto, posteriormente à aprovação da Lei $n^{\circ}$ 10.257, de 2001, e a produção de significativo material de referência para discussão. Nessa mesma concepção, a utilização do termo Regularização Fundiária possui baixa expressividade 
até 2005, adquirindo maior relevância apenas em 2007, portanto, após a estruturação da Política Nacional de Habitação a partir da aprovação do Sistema Nacional de Habitação.

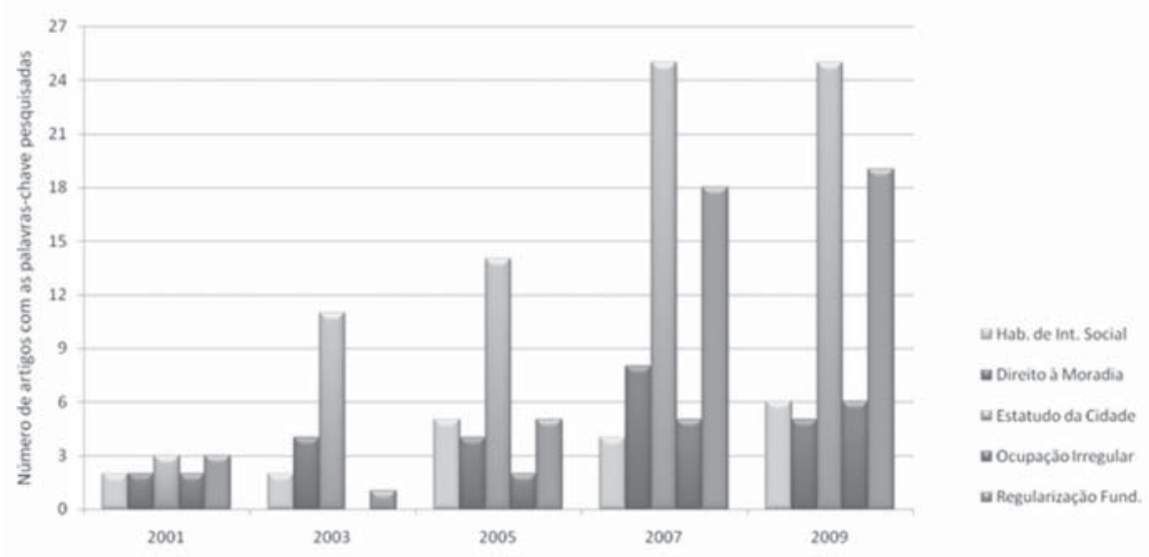

Fonte: ENANPUR (2001 - 2009). Elaboração dos autores.

\section{Gráfico 7. Uso das palavras-chave pesquisadas nos artigos aceitos na Enanpur, 2001 a 2009}

Complementarmente, o gráfico apresentado ainda revela um número baixo e constante de trabalhos envolvendo as palavras-chave Direito à Moradia e Ocupação Irregular. Para esses termos, acreditase haver uma redução do interesse em razão da histórica discussão desses assuntos tanto no meio acadêmico quanto na gestão pública. Dessa forma, especula-se um movimento gradativo de deslocamento desses termos do cerne dos trabalhos apresentados para elementos de contextualização de novos assuntos e discussões. Tal hipótese é corroborada pelos estudos de Kuhn (2011), o qual destaca o caráter progressivo do conhecimento que, após uma determinada revolução científica, passa a discutir outros problemas cuja existência sequer era cogitada pela geração anterior. Nas palavras do autor,

Poucos deles [os problemas discutidos na contemporaneidade] remontam ao início histórico da disciplina na qual aparecer atualmente. As gerações anteriores se ocuparam de seus próprios problemas, com seus próprios instrumentos e cânones de resolução. E não foram apenas os problemas que mudaram, mas toda a rede de fatos e teorias (KUHN, 2011, p. 180). 
Assim, embora o direito à cidade e à moradia - principal foco do Movimento Nacional da Reforma Urbana na década de 1970 - não tenha sido alcançado em sua plenitude, há relativo consenso entre o meio acadêmico e a sociedade sobre sua relevância. Destarte, já não se discute mais a função social da propriedade (direito à moradia) em si, mas, sim, de que forma alcançá-la (Estatuto da Cidade); já não se discute unicamente o fenômeno de formação de favelas (ocupação irregular), mas, sim, de que forma amenizar os problemas decorrentes de sua existência (regularização fundiária).

Complementarmente a essa discussão, verifica-se que as variações observadas são pouco expressivas dentro da totalidade dos trabalhos apresentados em cada edição do Enanpur. A questão habitacional, embora agregue um crescente número de trabalhos, ainda é pouco significativa no principal evento científico da área de PUR/D no Brasil (Gráfico 8).

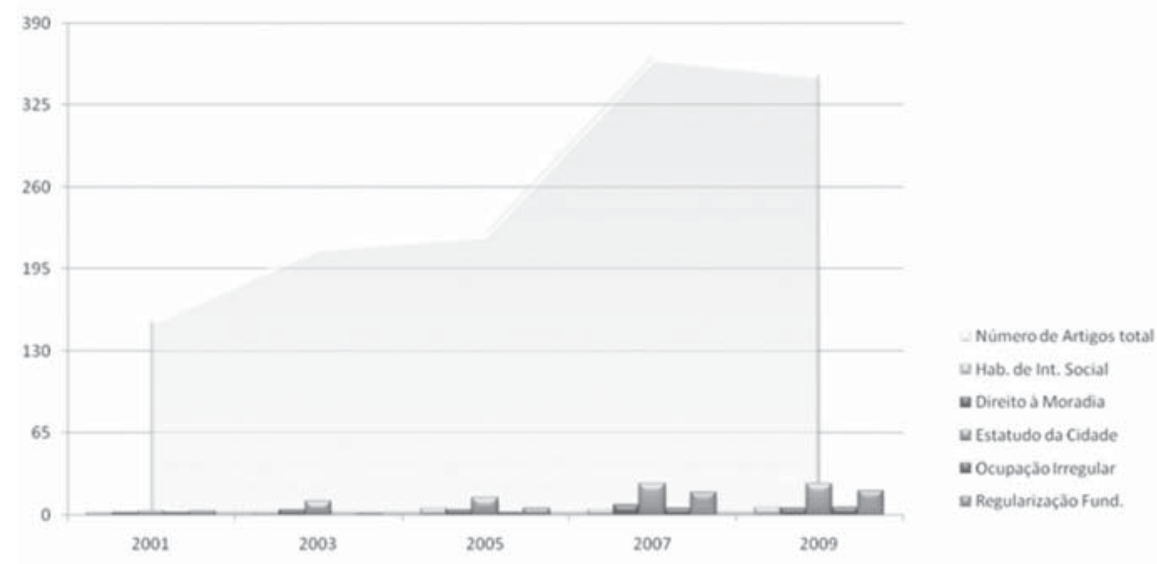

Fonte: Enanpur (2001 - 2009). Elaboração dos autores.

Gráfico 8. Uso das palavras-chave pesquisadas nos artigos aceitos na Enanpur e total de artigos publicados no evento, 2001 a 2009

\section{d. Rede de relacionamento entre pesquisadores}

O estudo bibliométrico até aqui empreendido concentrou seu escopo no volume da produção científica nacional sobre a temática 
habitacional dentro do universo de teses, dissertações, periódicos e eventos científicos. De forma que se consubstanciassem as evidências e reflexões oriundas das análises desenvolvidas, adotou-se a metodologia Análise de Redes Sociais como procedimento metodológico complementar, permitindo discutir a rede de autoria, de coautoria e de relacionamento entre os pesquisadores.

Para tanto, foram elencados os autores e coautores das publicações em periódicos e eventos científicos identificados por meio do levantamento bibliométrico apresentado anteriormente, englobando 231 pesquisadores e 188 artigos. Depois desse levantamento, a relação de pesquisadores e seus respectivos relacionamentos de autoria/ coautoria foram incluídos na plataforma do software UClnet, na qual os dados foram trabalhados.

Os resultados obtidos apontam para uma grande pulverização da autoria nos artigos publicados sobre habitação nos últimos dez anos. Conforme apresentado na Tabela 2, tanto em relação à autoria principal, como quanto à participação nos artigos (incluindo coautoria), os dados revelam um reduzido número de pesquisadores com recorrente presença, cuja quantidade é ainda menor quando considerados apenas os autores principais.

\section{Tabela 2. Pesquisadores segundo o número de artigos publicados} (autoria e coautoria)

\begin{tabular}{|lcl|llc|}
\multicolumn{1}{c}{$\begin{array}{c}\text { Participação } \\
\text { (autor ou coautor) }\end{array}$} & Artigos & $\%$ & \multicolumn{1}{c}{ Autoria Principal } & Artigos & $\%$ \\
\hline BALTRUSIS, Nelson & 5 & $1,6 \%$ & CARDOSO, Adauto L. & 4 & $2,1 \%$ \\
\hline ALVIM, Angélica A. T. B. & 4 & $1,3 \%$ & BALTRUSIS, Nelson & 4 & $2,1 \%$ \\
\hline CARDOSO, Adauto L. & 4 & $1,3 \%$ & MAGALHÃES, Alex F. & 3 & $1,6 \%$ \\
\hline FALCOSKI, Luis A. N. & 4 & $1,3 \%$ & ALVIM, Angélica A. T. B. & 3 & $1,6 \%$ \\
\hline BIENENSTEIN, Regina & 3 & $0,9 \%$ & BRASIL, Flávia de P. D. & 3 & $1,6 \%$ \\
\hline BRASIL, Flávia de P. D. & 3 & $0,9 \%$ & PEREIRA, Gislene F. & 3 & $1,6 \%$ \\
\hline $\begin{array}{l}\text { CASTRO, Carolina M. P. } \\
\text { de C. }\end{array}$ & 3 & $0,9 \%$ & LAGO, Luciana C. do & 3 & $1,6 \%$ \\
\hline FURTADO, Fernanda & 3 & $0,9 \%$ & BIENENSTEIN, Regina & 3 & $1,6 \%$ \\
\hline KATO, Volia R. C. K. & 3 & $0,9 \%$ & SOUZA, Ângela G. & 2 & $1,1 \%$ \\
\hline
\end{tabular}




\begin{tabular}{|c|c|c|}
\hline $\begin{array}{c}\text { Participação } \\
\text { (autor ou coautor) }\end{array}$ & Artigos & $\%$ \\
\hline LAGO, Luciana C. do L. & 3 & $0,9 \%$ \\
\hline MAGALHÃES, Alex F. & 3 & $0,9 \%$ \\
\hline PEREIRA, Gislene de F. & 3 & $0,9 \%$ \\
\hline AZEVEDO JR., Manoel T. & 2 & $0,6 \%$ \\
\hline BARROS, Joana & 2 & $0,6 \%$ \\
\hline BERGAMIN, Marta de A. & 2 & $0,6 \%$ \\
\hline BONDUKI, Nabil & 2 & $0,6 \%$ \\
\hline BRUNA, Gilda C. & 2 & $0,6 \%$ \\
\hline COBRA, Patricia L. & 2 & $0,6 \%$ \\
\hline COMPANS, Rose & 2 & $0,6 \%$ \\
\hline DENALDI, Rosana & 2 & $0,6 \%$ \\
\hline D'OTTAVIANO, Maria C. L. & 2 & $0,6 \%$ \\
\hline GALINDO, Evania F. & 2 & $0,6 \%$ \\
\hline GONDIM, Linda M. P. & 2 & $0,6 \%$ \\
\hline GOUVÊA, Denise de C. G. & 2 & $0,6 \%$ \\
\hline LAGE E LAGE, Selena D. & 2 & $0,6 \%$ \\
\hline LAY, Maria C. D. & 2 & $0,6 \%$ \\
\hline $\begin{array}{l}\text { MENEZES, Ednilson L. } \\
\text { S. M. }\end{array}$ & 2 & $0,6 \%$ \\
\hline MIRANDA, Lívia I. B. de & 2 & $0,6 \%$ \\
\hline NAKANO, Kazuo & 2 & $0,6 \%$ \\
\hline OLIVEIRA, Maria T. C. & 2 & $0,6 \%$ \\
\hline POLLI, Simone A. & 2 & $0,6 \%$ \\
\hline REFINETTI, Maria L. & 2 & $0,6 \%$ \\
\hline REZENDE, Vera F. & 2 & $0,6 \%$ \\
\hline RIBEIRO, Sandra B. & 2 & $0,6 \%$ \\
\hline RIZEK, Cibele S. & 2 & $0,6 \%$ \\
\hline SANTORO, Paula F. & 2 & $0,6 \%$ \\
\hline SILVA, Madianita N. da S. & 2 & $0,6 \%$ \\
\hline SILVA, Maria da G. P. & 2 & $0,6 \%$ \\
\hline SOUZA, Ângela G. & 2 & $0,6 \%$ \\
\hline SOUZA, Marcelo L. de & 2 & $0,6 \%$ \\
\hline TONELLA, Celene T & 2 & $0,6 \%$ \\
\hline $\begin{array}{l}\text { Demais autores } \\
\text { (apenas um artigo) }\end{array}$ & 217 & $68,7 \%$ \\
\hline Total $^{*}$ & 316 & $100 \%$ \\
\hline
\end{tabular}

\begin{tabular}{lcc}
\multicolumn{1}{c}{ Autoria Principal } & Artigos & $\%$ \\
\hline $\begin{array}{l}\text { CASTRO, Carolina M. } \\
\text { P. de }\end{array}$ & 2 & $1,1 \%$ \\
\hline TONELLA, Celene & 2 & $1,1 \%$ \\
\hline RIZEKE, Cibele S. & 2 & $1,1 \%$ \\
\hline GOUVÊA, Denise de C. & 2 & $1,1 \%$ \\
\hline MENEZES, Ednilson L. S. & 2 & $1,1 \%$ \\
\hline GALINDO, Evania F. & 2 & $1,1 \%$ \\
\hline FURTADO, Fernanda & 2 & $1,1 \%$ \\
\hline GONDIM, Linda M. P. & 2 & $1,1 \%$ \\
\hline MIRANDA, Livia I. B. de & 2 & $1,1 \%$ \\
\hline SOUZA, Marcelo L. de & 2 & $1,1 \%$ \\
\hline D'OTTAVIANO, Maria C. L & 2 & $1,1 \%$ \\
\hline SILVA, Maria da G. P. & 2 & $1,1 \%$ \\
\hline REFINETTI, Maria L. & 2 & $1,1 \%$ \\
\hline DENALDI, Rosana & 2 & $1,1 \%$ \\
\hline COMPANS, Rose & 2 & $1,1 \%$ \\
\hline LAGE E LAGE, Selena D. & 2 & $1,1 \%$ \\
\hline POLLI, Simone A. & 2 & $1,1 \%$ \\
\hline Demais autores & 126 & $67,0 \%$ \\
\hline (com apenas um artigo) & 188 & $100 \%$ \\
\hline Total & & \\
\hline & 2 & 2 \\
\hline
\end{tabular}

Fonte: Elaboração dos autores.

Nota: *Não se refere ao total de artigos.

Nesse contexto, apesar de não ser possivel identificar pesquisadores hegemônicos na temática, alguns se destacam por um 
número maior (embora restrito) de publicações, nas quais seu papel na condição de autor principal é predominante: Adauto L. Cardoso, Nelson Baltrusis, Alex F. Magalhães, Angélica Alvim, Flávia de P. Brasil, Gislene Pereira, Luciana Lago e Regina Bienenstein.

É importante ressaltar que esses resultados se referem unicamente ao recorte de análise desta pesquisa, não excluindo ou enaltecendo a relevância de determinados pesquisadores sobre os demais. Também é necessário salientar que a pesquisa se concentrou em periódicos e eventos científicos da área de PUR/D, área de concentração que, juntamente com a de Arquitetura e Urbanismo, concentra o maior volume de estudos relacionados à problemática habitacional. Assim, alguns pesquisadores de significativa proeminência na temática, como, por exemplo, Ermínia Maricato, Raquel Rolnik, Nabil Bonduki e Suzana Pasternak, tendem a não se destacar nesta pesquisa, haja vista que estão vinculados a programas de pós-graduação na área de Arquitetura e Urbanismo, direcionando, portanto, suas publicações para periódicos nessa área ${ }^{8}$. Complementarmente, Luiz Cesar de Queiroz Ribeiro, renomado pesquisador da questão habitacional no Brasil, também não se destaca neste trabalho por ser um dos editores-chefes do Cadernos Metrópole, periódico integrante da amostra de pesquisa.

Apesar das ressalvas, evidencia-se uma grande pulverização das publicações sobre a questão habitacional no principal evento e em dois dos principais periódicos da área de PUR/D no Brasil: entre 2000 e 2010, dos 188 artigos da amostra de pesquisa, 67\% foram elaborados por um pesquisador que não publicou mais nenhum outro trabalho no período.

Paralelamente à discussão sobre a predominância de determinados autores, também é interessante analisar a rede de relacionamento construída com base nos artigos cuja autoria envolvia mais de um pesquisador. Dos 231 artigos referentes à amostra desta pesquisa, $132(57,14 \%)$ apresentaram mais de um autor. Os relacionamentos entre estes 132 pesquisadores (autores e coautores) foram trabalhados no software NetDraw, do qual foram obtidos os sociogramas analisados na sequência.

${ }^{8}$ Especula-se que a área de concentração dos autores segundo o programa de pós-graduação ao qual estão vinculados, muitas vezes, delineia (ou condiciona) o encaminhamento da sua produção científica. 
A Figura 1 apresenta o sociograma da rede de pesquisadores sem distinção de relevância entre as relações de autoria e coautoria. Como pode ser observado, a grande maioria dos nós estabelece um número limitado de relações, oscilando, geralmente, entre um e dois outros pesquisadores. Quanto à representação gráfica, é possível visualizar elos direcionados (directed ties), que traduzem a relação de autoria (origem das flechas) e coautoria (destino das flechas).

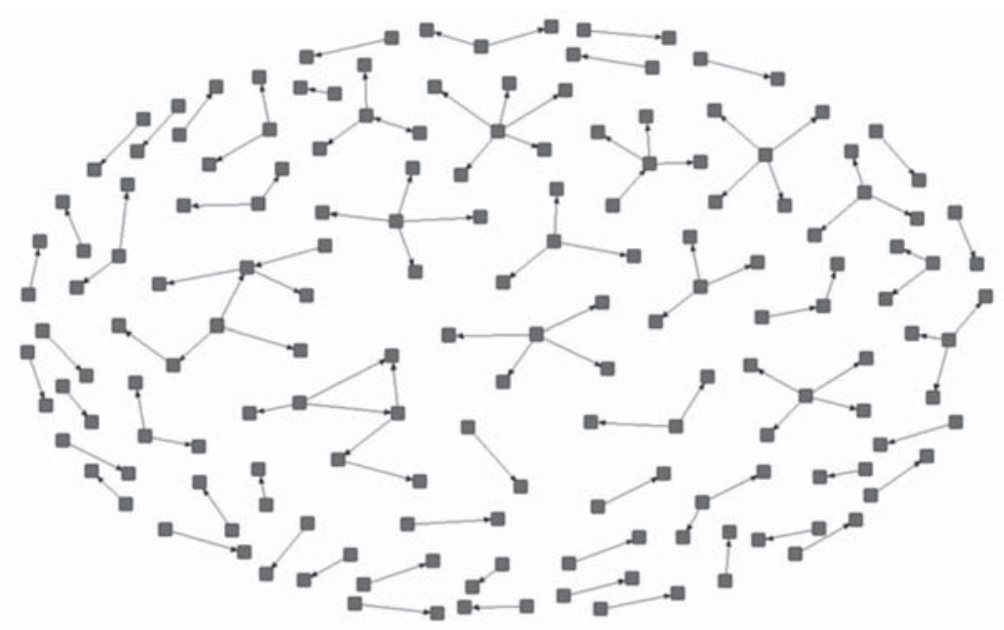

Fonte: Elaboração dos autores.

Figura 1. Sociograma da rede de pesquisadores com ao menos uma relação

Buscando um melhor entendimento das relações apresentadas, analisou-se a centralidade da rede de forma a verificar a importância ou recorrência de autores específicos na rede. Nesse ponto, vale citar Souza e Quandt, que afirmam o seguinte:

[...] atores são considerados mais centrais quando apresentam uma quantidade maior de relacionamentos com um número maior de atores da rede, ou desempenham um papel social caracterizado por alta conectividade com outros atores (2008, p. 34).

Destarte, no que se refere à quantidade de relações com autores diferentes, observa-se que um grupo pequeno se destaca (Tabela 3). Desse modo, 15 (11,36\%) dos 132 autores se sobressaíram, a saber: Regina Bienenstein, Ana Aleixo, Luiz Falcoski, Norma Lacerda, Maria 
Lay, Maria Sá, Letizia Vitale, Angélica Alvim, Aline Carvalho, Renato Cymbalista, José Francisco, Fernanda Furtado, Monica Hass, Gislene Pereira e Paula Santoro.

\section{Tabela 3. Quantidade de relações com pesquisadores diferentes}

\begin{tabular}{lcc} 
& Autor & Degree \\
\hline BIENENSTEIN, Regina & 5 \\
ALEIXO, Ana E. & 4 \\
\hline FALCOSKI, Luiz A. N. & 4 \\
\hline LACERDA, Norma & 4 \\
LAY, Maria C. D. & 4 \\
SÁ, Maria E. R. de & 4 \\
VITALE, Letizia & 4 \\
ALVIM, Angélica A. T. B. & 3 \\
\hline CARVALHO, Aline W. B. de & 3 \\
CYMBALISTA, Renato & 3 \\
FRANCISCO, José & 3 \\
FURTADO, Fernanda & 3 \\
HASS, Monica & 3 \\
\hline PEREIRA, Gislene & 3 \\
SANTORO, Paula F. & 3
\end{tabular}

Fonte: Elaboração dos autores.

Embora a estrutura geral de relacionamentos se apresente muito fragmentada, é possível identificar duas redes imbricadas que sinalizam para a existência de grupos de pesquisa dentro da amostra de artigos analisados, como evidenciado por um número representativo e variado de relações (Figura 2). A partir do levantamento do vínculo institucional desses pesquisadores, pode-se arriscar definir dois núcleos de pesquisa: um primeiro formado pelo eixo Faculdade de Arquitetura e Urbanismo da Universidade de São Paulo (FAU/USP) - Instituto Pólis, e outro aqui denominado USP São Carlos - Universidade Federal de São Carlos (UFSCar). É interessante observar que essas duas redes são compostas por pesquisadores de mesma localidade, denotando baixa integração de autores de diferentes estados e regiões do País.

Paralelamente, o sociograma apresentado na Figura 2 permite especular sobre a existência de importantes nós na rede, que se traduzem 
em cidades onde há uma concentração de pesquisadores voltados para a questão habitacional. Poder-se-ia citar: São Paulo, onde se destacam Renato Cymbalista e Nabil Bonduki; Curitiba, capitaneada por Gislene Pereira; São Carlos, com destaque para Luiz Falcoski; e Salvador, onde se ressalta Nelson Baltrusis. Deve-se salientar que essas cidades abrigam alguns dos principais centros de pesquisa sobre habitação no Brasil e, portanto, tendem naturalmente a se estabelecer como nós de destaque nesta análise. Apesar dessas evidências, as constatações realizadas constituem unicamente hipóteses, as quais devem ser aprofundadas em estudos futuros.

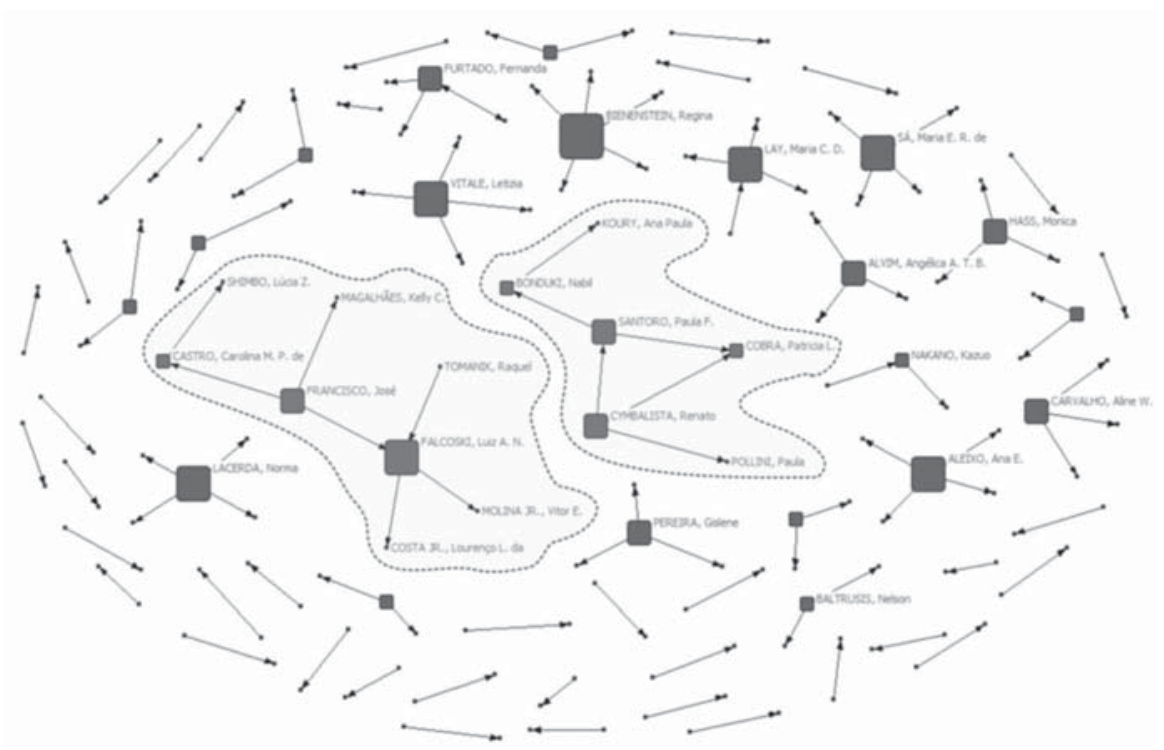

Fonte: Elaboração dos autores.

Figura 2. Sociograma da rede de pesquisadores por degree

${ }^{9}$ A produção científica nacional efetivamente acompanha a cronologia da política habitacional no Brasil ou há um descompasso entre o entendimento dos formuladores de políticas públicas e os pesquisadores acadêmicos?

\section{Considerações finais}

Compreender as tendências e os movimentos que balizam a produção científica nacional, distante de constituir uma tarefa simples e objetiva, está permeado de descaminhos e múltiplas interpretações. A questão-problema imposta nesta pesquisa ${ }^{9}$ revelou-se de complexa discussão, permitindo ao pesquisador unicamente ressaltar evidências, sugerir argumentos e levantar hipóteses. 
Não obstante, os estudos bibliométricos empreendidos, mesmo que solidamente fundamentados e com representatividade amostral, não são capazes de responder pelo universo do conhecimento científico sobre a questão habitacional no Brasil. Essa constatação configura uma das principais limitações da metodologia adotada, na qual é possível identificar uma relação naturalmente cíclica, em que a ampliação da amostra e das fontes de dados utilizadas conduz a uma nova aproximação da hipótese, que demanda novos aprofundamentos, em um continuum que se encerra em si próprio. Complementarmente, deve-se ressaltar que a escolha das palavras-chave possui relevante papel nos resultados obtidos, não sendo possivel efetuar conclusões afirmativas, mas apenas indicativas.

Independentemente dessa questão, salta aos olhos um panorama não muito animador para a resolução do deficit habitacional em nosso País. Em geral, evidencia-se um desencontro entre as ideias e os ideais debatidos no meio acadêmico e aqueles adotados pelos formuladores de políticas públicas. A produção científica nacional provou-se ainda muito tímida quando comparada à gravidade do problema habitacional nas cidades brasileiras. Discutem-se novos problemas, intenciona-se buscar novas soluções, mas pouco se transforma em termos de paradigmas, valores e instrumentos.

Nesse contexto, arrisca-se identificar um padrão, ainda que pessimista: a grande maioria das pesquisas desenvolvidas apresenta seu escopo centrado em temáticas exaustivamente debatidas, permanecendo em nichos pouco combativeis, onde a discussão de novos dados à luz de antigas teorias é frequentemente ostentada como original, não agregando contribuições relevantes ao conhecimento científico. Em outras palavras, torna-se complexo o grau de avaliação de determinado assunto, evidencia-se um número maior de variáveis, mas não se incorporam elementos inovadores que possam efetivamente contribuir na práxis da gestão pública.

Esse descolamento entre gestão pública e meio acadêmico, embora possa ser apregoado como responsável pelas grandes inovações tecnológicas e científicas da humanidade, também traz consigo uma 
face perversa, particularmente no campo da gestão urbana: discute-se muito, produz-se muito conhecimento, mas pouco se muda na sociedade, de tal forma que é inevitável questionar o alcance de nossa atuação na condição de pesquisadores para a superação da crônica segregação social que historicamente persiste no Brasil.

Sem a pretensão de encerrar os debates sobre a temática, este trabalho procurou contribuir com as investigações a respeito dos elementos e tendências caracterizadoras da construção do conhecimento científico sobre a temática habitacional no Brasil, fornecendo consistentes subsídios para a ampliação da discussão teórica e empírica a respeito da questão.

Acredita-se que as ideias discutidas possam servir de base para a produção de novos estudos, agregando indícios com vistas ao entendimento mais aprofundado de diferentes aspectos referentes à produção científica sobre a temática habitacional no Brasil e sua interseção com a gestão das cidades brasileiras. Por fim, é necessário salientar que os resultados obtidos e as conclusões ensaiadas neste trabalho não pretendem generalizar a comunidade científica ou ignorar os avanços alcançados nas últimas décadas, mas, sim, identificar um padrão, no qual se acredita que esses progressos se diluam no imenso volume da produção científica contemporânea.

Recebido em 30/07/2013 Aprovado em 20/11/2013 
Referências

ARAÚJO, C. A. Bibliometria: evolução histórica e questões atuais. Em Questão, Porto Alegre, v. 12, n. 1, p. 11-32, jan./jun. 2006.

ARAÚJO, R. F.; ALVARENGA, L. A bibliometria na pesquisa científica da pós-graduação brasileira de 1987 a 2007. Revista de Biblioteconomia e Ciência da Informação, Florianópolis, v. 16, n. 31, p. 51-70, 2011.

BONDUKI, N. Política habitacional e inclusão social no Brasil: revisão histórica e novas perspectivas no governo Lula. Revista eletrônica de Arquitetura e Urbanismo, São Paulo, n. 1, p. 70-104, 2008. Disponível em: <http://www.usjt.br/arq.urb/numero_01/artigo_05_180908.pdf>. Acesso em: jan. 2011.

BORGATTI, S. P.; EVERETT, M. G.; FREEMAN, L. C. Ucinet for Windows: Software for Social Network Analysis. Harvard, MA: Analytic Technologies, 2002.

CADERNOS METRÓPOLE. São Paulo: EDUC/PUC-SP, 2000-2010. Semestral.

CALDAS, M. P.; TINOCO, T. Pesquisa em gestão de recursos humanos nos anos 1990: um estudo bibliométrico. RAE, São Paulo, v. 44, n. 3, p. $100-114,2004$.

CASTIEL, L. D.; SANZ-VALERO, J. Entre fetichismo e sobrevivência: o artigo científico é uma mercadoria acadêmica? Cadernos de Saúde Pública, Rio de Janeiro, v. 23, n. 12, dez. 2007.

DUARTE, F.; FREY, K. Redes urbanas. In: DUARTE, F.; QUANDT, C.; SOUZA, Q. (eds.) $O$ tempo das redes. São Paulo: Perspectiva, 2008. p.155-177.

ENCONTRO NACIONAL DA ANPUR (ENANPUR), 2001-2009, Rio de Janeiro. Anais... Rio de Janeiro: ANPUR, 2001-2009. Bienal.

FERREIRA, J. S. W. Alcances e limitações dos instrumentos urbanísticos na construção de cidades democráticas e socialmente justas. Texto de 
apoio às discussões da $5^{a}$ Conferência das Cidades. Brasília: Ministério das Cidades, 2003.

FRANCELIN, M. M. Ciência, senso comum e revoluções científicas: ressonâncias e paradoxos. Revista Ciência da Informação, Brasília, v. 33, n. 3, p. 26-34, set./dez. 2004.

KUHN, T. S. A Estrutura das revoluções científicas. São Paulo: Perspectiva, 2011.

MARICATO, E. Brasil, cidades: alternativas para a crise urbana. 4. ed. Rio de Janeiro: Vozes, 2011.

MOCELIN, D. G. Concorrência e alianças entre pesquisadores: reflexões acerca da expansão de grupos de pesquisa dos anos 1990 aos 2000 no Brasil. RBPG, Brasília, v. 6, n. 11, p. 35-64, dez. 2009.

NASCIMENTO NETO, P.; MOREIRA, T. Análise de Redes Sociais aplicada aos Planos Locais de Habitação de Interesse Social: estudo de caso na região Sul do Brasil. In:CONGRESSO INTERNACIONAL SUSTENTABILIDADE E HABITAÇÃO DE INTERESSE SOCIAL, 2010, Porto Alegre. Anais... Porto Alegre: PUCRS, 2010.

RBEUR - Revista Brasileira de Estudos Urbanos e Regionais. UFRJ: ANPUR, 2000-2010. Semestral.

ROLNIK, R.; KLINK, J. Crescimento Econômico e desenvolvimento urbano: por que nossas cidades continuam tão precárias? Revista Novos Estudos CEBRAP, n. 89, p. 89-109, mar. 2011.

ROLNIK, R.; NAKANO, K; CYMBALISTA, R. Urban land and social housing in Brazil: the issue of land. In: Participatory Master Plans: the challenges of democratic management in Brazil: the right of the city. São Paulo: Instituto Pólis / Fundação Ford, 2008.

SÖTHE, A.; KROENKE, A.; BEZERRA, F. A. Evolução do Conhecimento contábil nos artigos científicos de contabilidade e finanças sob a visão epistemológica de Ludwik Fleck. In: SIMPÓSIO DE ADMINISTRAÇÃO DA 
PRODUÇÃO, LOGÍSTICA E OPERAÇÕES INTERNACIONAIS, 14., 2011, São Paulo. Anais... São Paulo: FGV, 2011.

SOUZA, Q.; QUANDT, C. Metodologia de análise de redes sociais. In. DUARTE, F.; QUANDT, C.; SOUZA, Q. (Eds.). 0 tempo das redes. São Paulo: Perspectiva, 2008. p. 31-63.

TONELLI, M.; CALDAS, M.; LACOMBE, B.; TINOCO, T. Produção acadêmica em Recursos Humanos no Brasil: 1991-2000. RAE, v. 43, n. 1, p. 105$122,2003$.

ULTRAMARI, C.; FIRMINO, R. J.; SILVA, S. F. P. Uma abordagem bibliométrica do estudo do planejamento urbano no Brasil nas décadas de 1990 e 2000. In: ENCONTRO NACIONAL DA ANPUR, 14., 2011, Rio de Janeiro. Anais... Rio de Janeiro: ANPUR, 2011.

WEITZEL, S. da R. O papel dos repositórios institucionais e temáticos na estrutura da produção científica. Em questão, Porto Alegre, v. 12, n. 1, p. 51-71, jan./jun. 2006. 